\title{
A CONTRIBUIÇÃO DO PODER JUDICIÁRIO NA EFETIVAÇÃO DAS AÇÕES AFIRMATIVAS PARA AMPLIAÇÃO DA REPRESENTATIVIDADE DE GÊNERO NA POLÍTICA
}

\author{
The Contribution of the Judiciary Branch to Ensure the Implementation of Affirmative \\ Actions and Expand Gender Representativeness in Politics
}

Luísa Hickel Gamba

Resumo: A legislação eleitoral tem estabelecido ações afirmativas para a participação da mulher na política ao longo dos anos das mais variadas formas. Para a efetivação dessas políticas afirmativas, entretanto, é fundamental que o Poder Judiciário, principalmente a Justiça Eleitoral, faça valer seus propósitos, quando provocado pelo não atendimento das reservas legais. O presente artigo tem por objetivo apontar as ações afirmativas estabelecidas na legislação eleitoral brasileira para ampliar a participação da mulher na política e apresentar os contornos de efetividade conferidos a cada uma delas pelos tribunais superiores. Com a compilação restam evidenciados não só os avanços e retrocessos da legislação eleitoral e a evolução da jurisprudência, capitaneada, sobretudo, pelas cortes superiores, mas, especialmente, a contribuição do Poder Judiciário na efetivação das ações afirmativas para ampliação da representatividade de gênero na política.

Palavras-chave: Ações afirmativas. Gênero. Mulheres. Participação na política.

\begin{abstract}
The electoral legislation has established different affirmative actions to increase women's participation in politics in the past few years. The Judicial branch, particularly the Electoral Justice, has to ensure that such policies are properly implemented when called to judge violations. This article presents affirmative actions designed to expand women's participation in politics in Brazil and discuss their effective implementation based on the superior courts' activities. The data compiled shows advances and setbacks of the electoral legislation, and the evolution of jurisprudence, emphasizing the role of the superior courts. The study highlights the judiciary branch's relevant contribution to the proper implementation of affirmative actions to expand gender representativeness in politics in Brazil.
\end{abstract}

Keywords: Affirmative actions. Gender. Women. Participation in politics. 


\section{Introdução}

A Organização das Nações Unidas (ONU), desde 2015, adota a Agenda 2030, contendo 17 objetivos de desenvolvimento sustentável (ODS) e 169 metas deles decorrentes, a serem alcançadas por todos os países integrantes ${ }^{1}$. O ODS 5 é "alcançar a igualdade de gênero e empoderar todas as mulheres e meninas". Com isso, o tema da igualdade de gênero ganhou atualidade e está em debate em todos os fóruns, sob os mais variados enfoques. Uma das metas estabelecidas para o ODS 5 é "garantir a participação plena e efetiva das mulheres e a igualdade de oportunidades para a liderança em todos os níveis de tomada de decisão na vida política, econômica e pública".

Em relação à política partidária, as instituições envolvidas com o processo eleitoral brasileiro, que se renova a cada dois anos com as eleições gerais e municipais alternadamente, também estão comprometidas com a agenda 2030 da ONU, sendo perceptíveis as alterações legislativas e os compromissos assumidos pelas instituições para diminuir a diferença de gê$n^{n} \mathrm{ro}^{2}$. Com efeito, a legislação eleitoral tem estabelecido ações afirmativas para ampliar a participação da mulher na política das mais variadas formas, sempre por estímulo dos compromissos internacionais assumidos pelo Brasil, e o Poder Judiciário, por sua vez, quando provocado pela falta de atendimento das reservas legais estabelecidas, tem evoluído seus julgados sempre no sentido de dar efetividade a essas políticas afirmativas, fazendo valer seus propósitos.

Desde a primeira alteração legislativa para o incremento da participação da mulher na política, em 1995, com o estabelecimento da reserva de vagas para as candidaturas femininas, muitos estudos foram feitos tendo como tema as cotas de gênero nas candidaturas, ora para definir a

\footnotetext{
${ }^{1}$ A agenda 2030 da ONU está disponível em: < https:// nacoesunidas.org/pos2015/agenda2030/>. Acesso em: 10 fev. 2020.

${ }^{2}$ A exemplo, a ONU Mulheres em parceria com o Tribunal Superior Eleitoral (TSE), o Instituto Patrícia Galvão (IPG) e o Grupo de pesquisa sobre Democracia e Desigualdades da Universidade de Brasília (Démodé/UnB) lançaram a plataforma "Cidade 50-50: todas e todos pela igualdade” para as eleições municipais de 2016, com o objetivo de que candidatas e candidatos assumissem compromissos públicos com os direitos das mulheres. A agenda "Cidade 50-50" tem como origem os Objetivos do Desenvolvimento Sustentável (ODS) e a iniciativa "Por um Plante 50-50 em 2030: um passo decisivo pela igualdade de gênero", lançada pela ONU Mulheres para promover a igualdade de gênero e a realização de todos os ODS. Disponível em: <https://www.cidade5050.org.br/>. Acesso em: 10 fev. 2020.
} 
natureza jurídica dessa medida, como ação afirmativa ou como condição de elegibilidade (MACEDO, 2014), ora para buscar os fundamentos para a discriminação positiva (AFANIO e VOLPATO, 2016; PORCARO, 2019; SAPI, 2020) ou para encontrar as razões do baixo incremento no número de mulheres nos cargos eletivos no período posterior à instituição das cotas (ARAÚJO, 2001; BONA e MAY, 2019) e propor medidas para vencê-las (SILVEIRA, 2019).

O presente artigo tem por objetivo geral apontar, para além das cotas de gênero nas candidaturas, todas as ações afirmativas estabelecidas na legislação eleitoral brasileira para ampliar a participação da mulher na política e apresentar os contornos de efetividade conferidos pelos tribunais superiores a cada uma delas, o que passou, inclusive, pelo estabelecimento dos meios processuais adequados para reprimir o descumprimento ou desvirtuamento dessas medidas, em face do limitado processo judicial eleitoral. Com efeito, as recentes decisões do Supremo Tribunal Federal (STF) e do Tribunal Superior Eleitoral (TSE) sobre o tema são um marco na efetividade dessas medidas, tanto pela possibilidade de fiscalização e punição do descumprimento das ações afirmativas da igualdade de gênero, como pela garantia da igualdade de oportunidades.

Para entender bem o tema, o artigo, inicialmente, apresenta as ações afirmativas, sob a perspectiva dos direitos humanos, ressaltando o contexto que justifica sua adoção. Em seguida, com fundamento em precedentes relevantes do Supremo Tribunal Federal, é apontado o tratamento jurisdicional que vem sendo dado às legislações que estabelecem ações afirmativas. Para complementar a parte teórica, são apresentados os fundamentos para a adoção de ações afirmativas de gênero para garantir a igualdade no exercício dos direitos políticos de votar e ser votado, os quais compõem o rol de direitos humanos. Por fim, são identificadas as ações afirmativas de gênero previstas na legislação eleitoral brasileira e apontados os contornos que lhes foram dados pelo Poder Judiciário na busca da sua maior efetividade.

\section{Revisão de literatura}

A pesquisa de que resultou o presente artigo foi realizada em duas linhas. A primeira, relativa à conceituação, objetivos e requisitos de validade das ações afirmativas, como gênero, para o que foram determinantes os textos de Piovesan $(2006,2005)$, que didaticamente as tratou sob a pers- 
pectiva dos direitos humanos, além da doutrina de Gomes (2001), Ikawa (2008), Rios (2008) e Rocha (1996). Nessa mesma linha, ainda, das ações afirmativas como gênero, a pesquisa foi também direcionada para a doutrina e, sobretudo, para as decisões paradigmáticas (leading cases) do Supremo Tribunal Federal (STF), que tratam da aplicação e interpretação das normas que estabelecem medidas afirmativas. Autores como Cambi (2019) e Streck (2008) deram os rumos da jurisdição constitucional no Estado Democrático de Direito e do papel transformador do Poder Judiciário na efetivação das políticas públicas. Por sua vez, dos julgados do STF pertinentes ao ponto, restou clara a constitucionalidade da legislação infraconstitucional que estabelece ações afirmativas, quando reconhecida a discriminação vivenciada por grupos identificados e quando as medidas propostas são proporcionalmente eficazes para afastá-la.

A segunda linha da pesquisa, relativa às ações afirmativas estabelecidas na legislação eleitoral brasileira, está fundada em artigos científicos sobre o tema, na própria legislação eleitoral e nos julgados paradigmáticos (leading cases) dos tribunais superiores que deram contorno e efetividade a essas medidas.

O importante histórico da lei de cotas feito por Sales e Walmisley (2020); o conceito de gênero apresentado por Afanio e Volpato (2016) e Severino (2019); a abordagem sobre as razões sociais e as fraudes responsáveis pelo insucesso inicial da lei de cotas para candidaturas feita por Bona e May (2019) e Araújo (2001); as referências e a análise de algumas das decisões judiciais paradigmáticas sobre a lei de cotas nas candidaturas, além do excelente histórico sobre a conquista dos direitos políticos pela mulheres feitos por Leite e Gundim (2019) e Ramos (2017); as experientes anotações de Macedo (2014) sobre as ações afirmativas estabelecidas na legislação eleitoral e sua qualificação jurídica; as razões e justificativas para a criação de ações afirmativas de gênero na política analisadas por Sapi (2020) e Porcaro (2019); a abordagem das decisões judiciais concretizadoras das ações afirmativas de gênero na política feita por Silveira (2019a e 2019b), Nascimento e Moreira (2019) e Gortari (2019); e a detalhada análise da lei de cotas nas candidaturas elaborada por Mattos, Cypriano e Brito (2007), tudo balizou a resposta para as questões da pesquisa apresentadas no texto. 


\section{Ações afirmativas e direitos humanos}

Como bem ensina Piovesan (2006, p. 8), a concepção contemporânea dos direitos humanos é marcada pela universalidade e pela indivisibilidade. Universalidade, porque basta a condição de pessoa para ser titular dos direitos, e indivisibilidade, porque, já não contemplando apenas os direitos civis e políticos, mas também os direitos econômicos, sociais e culturais, os direitos humanos constituem um todo e são interdependentes, de modo que a garantia de um é condição para a observância dos outros.

Permeando todos os direitos humanos fundamentais está a igualdade, como princípio garantidor de que todos terão as mesmas oportunidades de acesso e de exercício dos direitos fundamentais.

Em reforço à ideia de igualdade de oportunidades, a teoria moderna e multicultural dos direitos humanos compreende não só a defesa da igualdade de direitos, mas também o respeito às diferenças. Segundo Piovesan (2005, p. 47), "ao lado do direito à igualdade, está, também, como direito fundamental, o direito à diferença”. Isso significa que grupos vulneráveis, em situação de desigualdade em relação a qualquer direito fundamental, devem ter a seu favor não só estratégias de eliminação da discriminação, mas, especialmente, medidas de promoção da igualdade.

No plano das políticas públicas, mediante as quais são estabelecidos os meios e a forma de implementação dos direitos fundamentais e de entrega das prestações devidas pelo Estado, já não basta traçar e defender políticas universalistas, que busquem garantir a todos a igualdade formal. É imprescindível alcançar a igualdade material, levando em consideração a realidade de grupos ou minorias, que, por serem diferentes, sofrem discriminação no acesso à política pública universal.

Mais uma vez, Piovesan (2005, p. 48) auxilia ao assentar que a

discriminação significa toda distinção, exclusão, restrição ou preferência que tenha por objeto ou resultado prejudicar ou anular o exercício, em igualdade de condições, dos direitos humanos e liberdades fundamentais nos campos político, econômico, social, cultural, civil ou em qualquer outro campo. Logo, discriminação significa sempre desigualdade. 
A discriminação pode ser combatida com medidas punitivas que proíbem e sancionam atos discriminatórios negativos que prejudicam ou impedem o exercício de direitos ou o acesso às prestações devidas pelo Estado. Para equalizar as desigualdades, porém, muitas vezes é preciso fazer uma discriminação positiva, mediante a criação de medidas que possam compensar e superar as desvantagens sociais e históricas vivenciadas por alguns grupos, em razão de suas condições de gênero, raça, etnia, geração, orientação sexual, classe etc.

Ações, medidas ou políticas afirmativas, assim, são vantagens ou benefícios conferidos a indivíduos ou grupos discriminados para, mediante compensação de desvantagens, equalizar as oportunidades de acesso e de exercício dos direitos fundamentais.

Esse conceito é compartilhado pelos doutrinadores do tema, a exemplo de Gomes (2001, p. 131), Rios (2008, p. 191) e Piovesan (2005, p. 49), todos assinalando ainda que as ações afirmativas sempre têm como fundamento a igualdade material, como bem destaca Ikawa (2008, p. 152).

\section{Jurisdição constitucional e ações afirmativas}

Garantidoras da igualdade material, traduzida na igualdade de oportunidades no exercício dos direitos fundamentais, sejam eles civis, políticos, sociais, econômicos ou culturais, as regras que estabelecem ações afirmativas devem ser interpretadas de forma a lhes conferir ampla efetividade. Com efeito, a doutrina pertinente assinala que a jurisdição constitucional sobre as políticas públicas deve sempre buscar a maior efetividade dos diretos fundamentais ${ }^{3}$.

O STF já decidiu sobre a constitucionalidade de várias ações afirmativas estabelecidas na legislação infraconstitucional ${ }^{4}$. O julgamen-

${ }^{3}$ Por todos, de forma bem completa: CAMBI, Eduardo. Neoconstitucionalismo e neoprocessualismo: direitos fundamentais, políticas públicas e protagonismo judiciário. Almedina, 2019.

${ }^{4}$ Entre outros, na MC-ADI 1.276/SP (BRASIL, 1995), em que foi relator o ministro Otávio Gallotti, e no acórdão de mérito dessa mesma ADI (BRASIL, 2002), tendo como relatora a ministra Ellen Gracie, o STF admitiu a constitucionalidade de ação afirmativa estabelecida na legislação tributária do Estado de São Paulo, no sentido de conceder incentivo fiscal às empresas que contratam empregados com mais de 40 anos; no RMS 26.071 (BRASIL, 2008), relatado pelo ministro Ayres Britto, o STF decidiu pela constitucionalidade de ação afirmativa para portadores de deficiência; e na ADI 1.946 (BRASIL, 2003), de relatoria do ministro Sydney Sanches, foi afastada a limitação imposta ao salário materni- 
to paradigmático, entretanto, é o da ação de descumprimento de preceito fundamental (ADPF) 186, do Distrito Federal (BRASIL, 2014), no qual foi enfrentada a questão da constitucionalidade da política de cotas étnico-raciais instituída pela Universidade de Brasília. Nesse julgamento, a constitucionalidade das ações afirmativas foi fundamentada de forma ampla, em princípios e valores da Constituição Federal, tendo sido fixados ainda parâmetros para a validade constitucional dessas discriminações positivas.

Em síntese, o voto condutor do julgado, de relatoria do ministro Ricardo Lewandowski, assentou que as ações afirmativas buscam a igualdade material e que a igualdade de oportunidades é o próprio cerne da democracia; tem amplo respaldo no texto constitucional, não só nos dispositivos que expressamente as autorizam para grupos específicos (a exemplo do artigo 7을 inciso XX, que trata da proteção do mercado de trabalho da mulher, mediante incentivos específicos; e do artigo 37, inciso VII, que determina que a lei reservará percentual de cargos e empregos públicos para as pessoas portadoras de deficiência), mas, sobretudo, de forma ampla, nos objetivos fundamentais da República Federativa do Brasil, determinados no artigo 3ํ da Constituição Federal de 1988 (com destaque para o inciso IV, que coloca como objetivo fundamental a promoção do bem de todos, sem preconceitos de origem, raça, sexo, cor, idade e quaisquer outras formas de discriminação); e cumprem compromissos internacionais assumidos pelo Brasil, como na Convenção sobre a Eliminação de todas as Formas de Discriminação Racial e na Convenção sobre a Eliminação de Todas as Formas de Discriminação contra a Mulher, as quais expressamente estipulam a adoção dessas medidas.

Do referido voto (BRASIL, 2014, p. 45) ainda constou que a validade constitucional das ações afirmativas exige transitoriedade e proporcionalidade. Sobre a primeira exigência, convém transcrever o trecho do voto que refere que

as políticas de ação afirmativa fundadas na discriminação reversa apenas são legítimas se a sua manutenção estiver condicionada à persistência, no tempo, do quadro de exclusão social que lhes deu origem. Caso contrário, tais políticas poderiam converter-se em benesses permanentes, instituídas em prol de determinado grupo social, mas

dade pela EC 20/98, visto que contrária ao texto constitucional que coloca a proteção do trabalho da mulher, com incentivos específicos, como direito social. 
em detrimento da coletividade como um todo, situação - é escusado dizer - incompatível com o espírito de qualquer Constituição que se pretenda democrática.

Em relação à segunda exigência, o julgado assenta que "deve haver proporcionalidade entre os meios empregados e os fins colimados" (BRASIL, 2014, p. 46), observada a razoabilidade.

Esses requisitos de transitoriedade e proporcionalidade, embora não muito explorado esse aspecto no julgamento, são decorrência lógica da própria concepção da ação afirmativa, que, segundo a doutrina ${ }^{5}$, pressupõe reconhecimento ou identificação do grupo atingido pela discriminação, restrição ou exclusão social e distribuição dos benefícios que proporcionem a inclusão social. Uma vez alcançada a igualdade material que fundamenta a ação afirmativa, não tem mais lugar o reconhecimento e a distribuição que deram origem à medida.

\section{A necessidade de ações afirmativas de gênero no processo eleitoral brasileiro}

No Brasil, não obstante a Constituição da República estabeleça a igualdade entre homens e mulheres e autorize a adoção de discriminações positivas, conforme assinalado na seção anterior, o estabelecimento de ações afirmativas de gênero sempre foi inspirado pelos compromissos internacionais assumidos pelo Brasil, sem desmerecer os movimentos feministas nacionais ${ }^{6}$ que neles sempre marcaram presença.

Com efeito, as convenções e tratados internacionais, como a Convenção sobre a Eliminação da Discriminação contra a Mulher, de 1979, internalizada no Brasil primeiro, com reservas, pelo Decreto 89.460, de 1984, e depois, sem reservas, pelo Decreto 4.377, de 2002, e as metas e planos de ação estabelecidos pela ONU para a eliminação da discriminação contra a mulher e para a promoção da igualdade de gênero, frutos das quatro Confe-

\footnotetext{
${ }^{5}$ Nesse sentido, a doutrina de Piovesan (2005, p. 47), citando Nancy Fraser e Boaventura de Souza Santos.

${ }^{6}$ É de se adotar a definição de Matos, Cipriano e Brito (2007, p. 5), para os quais "os movimentos feministas per se são aqueles que procuram desnaturalizar os papéis de gênero, entre homens e mulheres, e procuram desfazer as relações hierárquicas entre esses, além de procurar expandir todos os direitos e capacidades às mulheres". No artigo consta ainda o histórico da dinâmica desses movimentos no Brasil.
} 
rências Mundiais sobre a Mulher ${ }^{7}$, bem como os atuais 17 objetivos de desenvolvimento sustentável que constituem a agenda 2030 da ONU, entre os quais está a igualdade de gênero (ODS 5), expressamente sugerem a adoção de ações afirmativas de gênero, reconhecendo a vulnerabilidade do grupo.

Isso aconteceu com a legislação eleitoral brasileira, que, para fazer valer compromissos internacionais, passou a estabelecer, a partir de 1995, logo após a Conferência Mundial sobre a Mulher realizada em Pequim, ações afirmativas de ampliação da participação da mulher na política das mais variadas formas. Bona e May (2019), Nascimento e Moreira (2019) e Matos, Cypriano e Brito (2007) avaliam esse processo.

É que a discriminação de gênero, incluindo, no que interessa ao presente artigo, o acesso restrito e dificultado da mulher aos direitos políticos, e acima de tudo, ao direito de ser eleita para os cargos de representação política, foi reconhecida na esfera internacional exatamente por estar presente na maioria dos países.

No Brasil, além de a mulher só ter conquistado o direito de voto em 1932, com o Código Eleitoral aprovado pelo Decreto no 21.076, de 24 de fevereiro de 1932, os dados estatísticos também revelam a baixa representatividade das mulheres nos cargos do legislativo, para os quais foi criada a política de cotas. Para se ter uma ideia, nas duas últimas eleições (2016 - municipais e 2018 - gerais) as mulheres eram maioria na população e no eleitorado, a cota mínima de candidaturas foi observada, mas ainda assim, o percentual de mulheres eleitas para os cargos do Legislativo não passou de $15 \%{ }^{8}$.

Porcaro (2019, p. 136-137) sintetiza, ao assinalar que "a desigualdade entre homens e mulheres na participação no poder político e nas instâncias decisórias é um problema histórico e mundial", além de ser "uma questão de direitos humanos que precisa ser corrigida por meio de políticas públicas", mas que não afasta "a necessidade de apresentar fundamentos teóricos da importância dessa participação”. Afanio e Volpato (2016) também abordam as justificativas jurídicas para a adoção de ações afirmativas de ampliação da participação das mulheres na política.

\footnotetext{
${ }^{7}$ Sobre as conferências mundiais sobre a mulher e os avanços obtidos em cada uma delas ver: <http://www.onumulheres.org.br/planeta5050-2030/conferencias/>. Acesso em: 10 fev. 2020.

${ }^{8}$ Estatísticas Eleitorais 2016 e 2018 - Candidatura e Eleitorado. Tribunal Superior Eleitoral, Brasília, DF. Disponível em: < http://www.tse.jus.br/eleicoes/estatisticas/estatisticas-eleitorais>. Acesso em: 08 maio 2019.
} 
De plano, a ampliação do número de mulheres nos cargos garante a igualdade de exercício dos direitos políticos de votar, ser votado e participar do processo eleitoral em igualdade de condições, os quais compõem o rol dos direitos humanos fundamentais. Também restam garantidos o pluralismo político e a representatividade, em todas as suas formas, não só numérica em fóruns de decisão (representação descritiva), mas também pela defesa de interesses pertinentes (representação substantiva), o que dá legitimidade e qualidade à democracia. Por fim, as ações afirmativas de promoção da igualdade de gênero na política pressupõem e ao mesmo tempo contribuem para o reconhecimento das mulheres como membros de um mesmo grupo que sofre discriminação a ser superada.

\section{Ações afirmativas de gênero na legislação eleitoral brasileira - avanços e retrocessos}

Cabe apresentar as ações afirmativas para ampliação da representatividade de gênero na política estabelecidas na legislação eleitoral brasileira em ordem cronológica, para pontuar os avanços e retrocessos.

No rastro da IV Conferência Mundial sobre a Mulher, organizada pela ONU entre 4 e 15 de setembro de 1995 em Pequim, a Lei no 9.100, de 29 de setembro 1995, estabeleceu a primeira ação afirmativa para ampliação da representatividade feminina na política, ao prever, no art. $11, \int 3^{\circ}$, que $20 \%$ (vinte por cento), no mínimo, das candidaturas para o pleito proporcional (cargos eletivos do Poder Legislativo) deveriam ser preenchidas por mulheres. A cota foi naquela oportunidade estabelecida apenas para as eleições municipais de 1996. Interessante anotar que no mesmo dispositivo legal constou a ampliação do número de candidaturas por partido ou coligação, em até 120\% (cento e vinte por cento) do número de vagas na Câmara Municipal.

$\mathrm{Na}$ Lei $\mathrm{n}^{\circ}$ 9.504, de 1997, as cotas de gênero foram estabelecidas para todas as eleições, municipais e gerais, a partir de $1998^{9}$, dispondo o art. $10, \int 3^{\circ}$, que cada partido ou coligação deveria reservar o mínimo de $30 \%$ (trinta por cento) e o máximo de 70\% (setenta por cento) das candidaturas para cada sexo no pleito proporcional (cargos eletivos do Poder Legislati-

\footnotetext{
${ }^{9}$ Em disposição transitória, o art. 80 da Lei no 9.504, de 1997, estabeleceu que, "nas eleições a serem realizadas no ano de 1998, cada partido ou coligação deverá reservar, para candidatos de cada sexo, no mínimo, $25 \%$ (vinte e cinco por cento) e, no máximo, $75 \%$ (setenta e cinco por cento) do número de candidaturas que puder registrar."
} 
vo). Assim como na Lei 9.100, de 1995, o mesmo dispositivo legal ampliou o número de candidaturas por partido, desta feita em até 150\% (cento e cinquenta por cento) do número de vagas a preencher em cada Casa Legislativa.

A propósito, Leite e Gundim (2019, p. 147) ponderam que,

a formulação de cotas partidárias com percentual igual ao aumento das vagas totais que cada partido pode registrar de 30\% (trinta por cento) na disputa eleitoral indica, de forma explícita, que os legisladores temiam a redução das candidaturas masculinas e adotaram essa medida como precaução para que não perdessem seu "espaço" no cenário político.

Sobreveio a Lei n⿳⺈ 12.034, de 2009, que alterou a redação do art. 10, \ $3^{\circ}$, da Lei no 9.504, de 1997, para dar maior efetividade às cotas, as quais deixaram de ser apenas uma reserva, sem obrigatoriedade no preenchimento, e passaram a ser cotas de candidatura de preenchimento obrigatório. Com efeito, o referido dispositivo, com a nova redação, estabelece que "cada partido ou coligação preencherá o mínimo de 30\% (trinta por cento) e o máximo de 70\% (setenta por cento) para candidaturas de cada sexo", no pleito proporcional (cargos eletivos do Poder Legislativo).

A Lei $n^{\circ}$ 12.034, de 2009, alterou também a Lei ํㅜㅇ.096, de 1995, para estabelecer, no art. 44, que, no mínimo, 5\% (cinco por cento) das receitas do Fundo Partidário fossem aplicados na criação e manutenção de programas de promoção e difusão da participação política das mulheres, e, no art. 45, que, no mínimo, 10\% (dez por cento) do tempo de propaganda partidária gratuita fossem dedicados a promover e difundir a participação política feminina.

Por sua vez, a Lei no 12.891, de 2009, acrescentou o art. 93-A na Lei n⿳⺈ 9.504, de 1997, para facultar ao TSE a utilização do horário de propaganda eleitoral gratuita, no período compreendido entre $1^{\circ}$ de março e 30 de junho dos anos eleitorais, para promover propaganda institucional, em rádio e televisão, destinada a incentivar a igualdade de gênero e a participação feminina na política.

Estendendo as cotas para além das candidaturas, mas com redu-

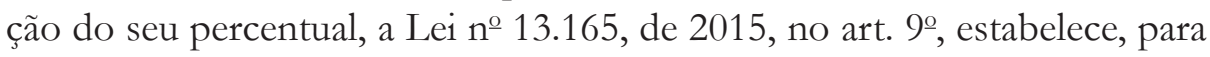
as três eleições seguintes à sua publicação, a reserva de no mínimo 5\% (cinco por cento) e no máximo 15\% (quinze por cento) dos recursos do Fundo 
Partidário para o financiamento das campanhas de candidatas mulheres. A mesma lei, alterando mais uma vez a redação do art. 45 da Lei nº 9.096, de 1995, ainda estendeu para as inserções anuais dos partidos políticos nas redes nacionais e nas emissoras estaduais a reserva de 10\% (dez por cento) do tempo de propaganda partidária gratuita para a promoção e difusão da participação política feminina. Por fim, em retrocesso das ações afirmativas, a mesma lei acrescentou os $\iint 5^{\circ}-\mathrm{A}$ e $7^{\circ}$ ao art. 44 da Lei noำ 9.096, de 1995, para dispor que os recursos do Fundo Partidário não utilizados na criação e manutenção de programas de promoção e difusão da participação política das mulheres poderiam ser acumulados em conta específica, por mais de uma exercício financeiro, para utilização futura em campanhas eleitorais de candidatas do partido, além de reduzir o tempo de propaganda institucional do TSE destinada a incentivar a igualdade de gênero e a participação feminina na política estabelecido no art. 93-A da Lei n⿳ำ 9.504, de 1995.

Com a criação do Fundo Especial de Financiamento de Campanha (FEFC), incrementando o financiamento público das campanhas partidárias, a Lei $\mathrm{n}^{\mathrm{O}}$ 13.487, de 2017, extinguiu a propaganda partidária e revogou as disposições legais que reservavam parte dela para a promoção e difusão da participação política feminina.

Por sua vez, a Lei n 13.831 , de 2019, anistiou os partidos políticos que até o exercício de 2018 não tivessem cumprido com a aplicação de, no mínimo, 5\% (cinco por cento) das receitas do Fundo Partidário na criação e manutenção de programas de promoção e difusão da participação política das mulheres, ao acrescentar à Lei $\mathrm{n}^{2} 9.096$, de 995 , o art. 55-C, com a seguinte redação: "A não observância do disposto no inciso V do caput do art. 44 dessa lei até o exercício de 2018 não ensejará a desaprovação das contas."

Como se vê, a legislação avançou da simples reserva de vagas para a candidatura de mulheres, passando pelo preenchimento obrigatório das cotas de gênero e a instituição de programas de incentivo da participação política feminina, até a reserva de recursos para as campanhas de candidatas mulheres. Os retrocessos também foram sentidos, muitos deles sem uma avaliação da efetividade das medidas afirmativas e, com certeza, sem que o objetivo da igualdade de gênero tivesse sido alcançado na política. 


\section{Efetivação judicial das ações afirmativas de gênero no processo eleitoral brasileiro}

O Poder Judiciário, por meio da Justiça Eleitoral, fiscaliza o cumprimento das ações afirmativas para igualdade de gênero na política, aplica as sanções devidas pelo seu descumprimento, mas, mais do que isso, por meio da interpretação e aplicação da lei, essencialmente, no exercício da jurisdição constitucional, estabelece os contornos e alcance dessas políticas afirmativas.

Assim, a compreensão das ações afirmativas para ampliação da representatividade de gênero na política exige o conhecimento das decisões judiciais que marcaram a efetividade dessas medidas, dando-lhes concretude. Com efeito, o Judiciário brasileiro tem sido provocado em relação a cada uma das regras protetoras da igualdade de gênero estabelecidas na legislação eleitoral, sendo bem visível a evolução da jurisprudência para efetivá-las, capitaneada, sobretudo, pelas cortes superiores. Cabe anotar ainda que, em face do limitado processo eleitoral brasileiro, os tribunais tiveram que definir até mesmo os meios processuais adequados para a judicialização do descumprimento das reservas legais, de modo a garantir o acesso à Justiça nessas situações.

Cabe, então, fazer a compilação dos meios processuais, das sanções estabelecidas para forçar o cumprimento das normas e das principais decisões judiciais que deram efetivação às ações afirmativas da igualdade de gênero na política.

A reserva de 5\% (cinco por cento) dos recursos do Fundo Partidário para a criação e manutenção de programas de promoção e difusão da participação política das mulheres é fiscalizada ordinariamente pela Justiça Eleitoral, por meio dos processos de prestação de contas, nos quais são aplicadas as sanções previstas em lei para essa falta, especialmente aquela prevista no $\int 5^{\circ}$ do art. 44 da Lei no 9.096, de 1995 (aumento do percentual de reserva de recursos do Fundo Partidário para a mesma finalidade), além da desaprovação das contas partidárias, com a aplicação da sanção prevista no $\int 3^{\circ}$ do art. 37 da Lei n⿳9 9.096, de 1995, conforme estabelecido pelo TSE no julgamento da prestação de contas (PC) no 283-29.2014.6.00.0000/DF (BRASIL, 2019a), em fevereiro de 2019. Bem por isso, a anistia concedida pela Lei n⿳o 13.831 , de 2019, representou um retrocesso na efetivação da igualdade de gênero na política, como assinalado acima. 
Também se resolvia na aplicação de sanção pelo Judiciário ( $\sqrt{ } 2^{\circ}$ do art. 45 da Lei no 9.096, de 1995), a falta de observância pelos partidos políticos do percentual mínimo de 10\% do tempo de propaganda partidária gratuita para a promoção e difusão da participação política feminina. Nesse sentido, o plenário do TSE, em setembro de 2016, cassou o tempo de propaganda partidária, no rádio e televisão, de três diretórios estaduais (2 do RS e 1 de MG), e em fevereiro de 2017, de dez partidos políticos que descumpriram a regra. $\mathrm{Na}$ ocasião do julgamento do recurso especial eleitoral (REspe) no 0000125-52.2015.6.21.0000/RS (BRASIL, 2018b), o relator, ministro Herman Benjamin, enfatizou que o intuito da lei não é usar o tempo da propaganda político-partidária para informar às mulheres o que vem sendo proposto em seu favor nas casas legislativas por seus representantes do sexo masculino, ou promover campanhas sobre os direitos das mulheres, mas, sim, incentivá-las a se engajarem na vida partidária. Essa reserva legal foi revogada pela Lei no 13.487 , de 2017, que criou o Fundo Especial de Financiamento de Campanha (FEFC) e extinguiu a propaganda partidária gratuita.

Em relação aos percentuais mínimo e máximo de recursos do Fundo Partidário para o financiamento de campanhas de candidaturas femininas, estabelecidos no art. 9ำ da Lei $n^{\circ} 13.165$, de 2015, o STF decidiu, por maioria de votos, que a distribuição de recursos desse fundo para o financiamento das campanhas eleitorais direcionadas às candidaturas de mulheres deve ser feita na exata proporção das candidaturas de ambos os sexos, respeitado o patamar mínimo de 30\% (trinta por cento) de candi-

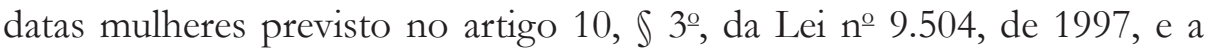
proporcionalidade do número de candidaturas femininas, caso esse percentual mínimo seja ultrapassado. Isso se deu no julgamento da ação direta de inconstitucionalidade (ADI) $\mathrm{n}^{\circ}$ 5.617/DF (BRASIL, 2018a), em março de 2018, tendo o plenário daquele tribunal decidido ainda que é inconstitucional a fixação de prazo para essa regra, como determinado na lei, visto que a distribuição não discriminatória deve perdurar enquanto for justificada a necessidade de composição mínima das candidaturas femininas, bem como são inconstitucionais os $\iint 5^{\circ}-\mathrm{A}$ e $7^{\circ}$ acrescentados pela mesma lei ao art. 44 da Lei no 9.096, de 1995, na parte em que autorizam que os recursos do Fundo Partidário não utilizados na criação e manutenção de programas de promoção e difusão da participação política das mulheres sejam utilizados em campanhas eleitorais de candidatas do partido. Nesse julgamento, o re- 
lator, ministro Edson Fachin, deixou bem claro que "o Supremo Tribunal Federal, ao examinar as alegações de inconstitucionalidade de norma, deve fixar a interpretação que constitucionalmente a densifique, a fim de fazer incidir o conteúdo normativo cuja efetividade independe de ato do Poder Legislativo."

$\mathrm{Na}$ linha da decisão do STF sobre as cotas de gênero na distribuição do Fundo Partidário para financiamento de campanha, o TSE, em maio de 2018, respondendo à consulta formulada por um grupo de parlamentares (consulta PJe n 0600252-18.2018.6.00.0000/DF) (BRASIL, 2018c), decidiu que também na distribuição do Fundo Especial de Financiamento de Campanha (FEFC) pelo menos 30\% (trinta por cento) dos recursos devem ser destinados para financiar as candidaturas femininas, assim como o mesmo percentual deve ser aplicado em relação ao tempo de propaganda eleitoral gratuita no rádio e TV.

Por fim, ainda em relação às cotas de gênero na distribuição dos fundos públicos para financiamento de campanhas eleitorais, também merece registro o julgamento pelo TSE, em agosto de 2019, do agravo de instrumento (AI) nº 339-86.2016.6.21.0039/RS (BRASIL 2019b), no qual restou decidido que a doação por candidata destinatária de recursos decorrentes da cota de gênero nos fundos públicos de financiamento de campanha configura desvio de finalidade suficiente para acarretar a cassação dos eleitos envolvidos com a prática. Também aqui, a efetivação da política afirmativa é reforçada pelo Judiciário.

Em relação às cotas de gênero, a Justiça Eleitoral começou a aplicar a ação afirmativa na apreciação dos requerimentos de registro de candidatura e nas impugnações a esses registros.

Para tanto, o TSE ressaltou a diferença dos comandos contidos na redação original do $\int 3^{\circ}$ do art. 10 da Lei no 9.504, de 1997 e aquela conferida pela Lei no 12.034 , de 2009, firmando o caráter imperativo desta última, e decidiu que o cálculo dos percentuais de 30\% (trinta por cento) e 70\% (setenta por cento) para cada sexo deverá considerar o número de candidatos efetivamente lançados pelo partido ou coligação, não se levando em conta os limites máximos permitidos de candidatura (150\% dos cargos). Decidiu ainda que, não atendidos os respectivos percentuais, cabe ao partido, dentro do prazo de registro, ajustar e regularizar os percentuais, sob pena de indeferimento dos registros de candidatura. A decisão paradigma 
desse entendimento é a proferida no recurso especial eleitoral (REspe) $\mathrm{n}^{\mathrm{o}}$ 784-32.2010.6.14.0000/PA, julgado em agosto de 2010 (BRASIL, 2010).

Digna de nota é ainda a resposta do TSE à consulta nº 0604054 58.2017.6.00.0000/RN (BRASIL 2018d), na qual foi decidido que a expressão "sexo", contida no $\int 3^{\circ}$ do art. 10 da Lei no 9.504, de 1995, refere-se a gênero e não ao sexo biológico (AFANIO e VOLPATO, 2016, p. 398; e SEVERINO, 2019, p. 280). Naquele julgado, o relator, ministro Tarcísio Vieira, ressaltou que "a construção do gênero representa fenômeno sociocultural que exige a abordagem multidisciplinar a fim de conformar uma realidade ainda impregnada por preconceitos e estereótipos geralmente de caráter moral e religioso aos valores e garantias constitucionais".

Nesse rumo, as decisões que indeferem o registro de candidatura que não observa as cotas de gênero resolvem apenas o cumprimento formal da política pública afirmativa, mas não o seu cumprimento material, havendo a possibilidade de as candidaturas não serem efetivas.

Inicialmente, em face do limitado processo judicial eleitoral ${ }^{10}$, era preciso definir a via processual adequada para provocar o Judiciário quando o descumprimento da ação afirmativa fosse visível apenas depois do deferimento do registro, seja por meio de renúncia ou desistência de candidatura que desequilibrasse a cota mínima, seja por meio da configuração da candidatura fictícia.

Em relação à renúncia de candidaturas femininas após o deferimento do respectivo registro, resultando em desequilíbrio das cotas de gênero, o TSE assumiu postura de neutralidade, ao decidir, no julgamento do recurso especial eleitoral (REspe) nº 214-98.2012.6.21.0091/RS (BRASIL, 2013), em março de 2013, que,

se, no momento da formalização das renúncias por candidatas, já tinha sido ultrapassado o prazo para substituição das candidaturas, previsto no art. $13, \sqrt{ } 3^{\circ}$, da Lei no $9.504 / 97$, não pode o partido ser penalizado, considerando, em especial, que não havia possibilidade jurídica de serem apresentadas substitutas, de modo a readequar os percentuais legais de gênero ${ }^{11}$.

\footnotetext{
${ }^{10} \mathrm{O}$ processo judicial eleitoral tem poucos tipos de ações judiciais e todas com objeto bem delimitado em lei. Macedo (2014) e Gortari (2019) tratam da dificuldade do acesso à judicialização das cotas de gênero na política pela limitação do processo judicial eleitoral.

${ }^{11}$ MACEDO (2014) critica a decisão, assinalando a perda da oportunidade para dar maior efetividade à ação afirmativa.
} 
Em relação às candidaturas fictícias ou "laranjas", por outro lado, o TSE assumiu posição protagonista, decidindo no recurso especial eleitoral (REspe) no 1-49.2013.6.18.0024/PI (BRASIL, 2015), em agosto de 2015, pela ampliação do conceito de fraude, no qual se insere a fraude na composição e cotização das candidaturas, permitindo sua apuração e desconstituição por meio da ação de impugnação de mandato eleitoral (Aime), e mais adiante, no julgamento do recurso especial eleitoral (REspe) no 24342.2012.6.18.0024/PI (BRASIL, 2016), em agosto de 2016, que a apuração da fraude no registro de candidaturas fictícias ou "laranja" também poderia ser objeto da ação de investigação eleitoral (Aije), quer sob o enfoque do abuso do poder político, quer sob o enfoque mesmo da fraude ${ }^{12}$.

Esses dois julgados paradigmáticos apenas estabeleceram meios processuais adequados de apuração do descumprimento material das cotas de gênero, garantindo o acesso à Justiça. As consequências ou sanções aplicadas ao comprovado descumprimento material das cotas de gênero nas candidaturas, em decorrência lógica, passaram a ser as mesmas previstas para os casos de procedência da Aime ou da Aije. Com efeito, em setembro de 2019, o TSE, no julgamento do recurso especial eleitoral (REspe) no 193-92.2016.6.18.0018/PI (BRASIL, 2019c), assentando que a fraude se deu no momento do registro das candidaturas, cassou esses registros e, consequentemente, os mandatos de todos os eleitos no pleito proporcional ${ }^{13}$, além de decretar a inelegibilidade daqueles comprovadamente envolvidos na fraude, porquanto se tratava de Aije.

\section{Conclusão}

As ações afirmativas, políticas afirmativas ou discriminações positivas constituem medidas para a compensação e superação de desigualdades no exercício de direitos fundamentais, as quais encontram respaldo no texto constitucional e nos compromissos internacionais assumidos pelo Brasil.

O reduzido número de mulheres nos cargos eletivos de representação, conforme dados estatísticos da própria Justiça Eleitoral, é o sinal mais evidente da existência da discriminação de gênero na política e da necessidade da instituição de ações afirmativas que proporcionem igualdade de oportunidades ao acesso e exercício dos direitos políticos das mulheres, notadamente do direito de ser eleita.

${ }^{12}$ GORTARI (2019, p. 197) trata da diferença entre as duas ações.

${ }^{13}$ SILVEIRA (2019), antes do julgamento, faz contundente defesa da preservação dos mandatos das mulheres eleitas, objetivo da política afirmativa sob apreciação judicial.

Resenha Eleitoral (Florianópolis), v. 24, n. 2, p. 117-138, 2020 
Não obstante as cotas de gênero no registro de candidaturas para os cargos eletivos do Poder Legislativo seja a ação afirmativa mais conhecida, existem na legislação eleitoral brasileira outras políticas públicas afirmativas para ampliar a representatividade de gênero na política.

O Poder Judiciário, sobretudo os tribunais superiores, tem dado importante contribuição para a efetividade dessas medidas de política afirmativa, atribuindo-lhes contornos que procuram vencer as dificuldades encontradas para a concretude da igualdade de gênero na política.

Ainda assim, há pontos que precisam ter melhor tratamento, principalmente, para a proteção do grupo discriminado. Nesse sentido, é preciso investir na fixação de parâmetros mais seguros para a configuração da fraude nas candidaturas e nos meios de prova da autoria, visto que, na maioria dos casos a prova tem exposto apenas as mulheres, destinatárias da norma afirmativa.

\section{Referências}

AFANIO, Claudia; VOLPATO, Eliane Bavaresco. A questão da ineficácia das ações afirmativas previstas no inciso V, artigo 45, da Lei dos Partidos Políticos e no $\int 3^{\circ}$, artigo 10, da Lei no 9.504/1997. Paraná Eleitoral: revista brasileira de direito eleitoral e ciência política, Curitiba, v. 5, n. 3, p. 393-411, 2016.

ARAÚJO, Clara. As cotas por sexo para a competição legislativa: o caso brasileiro em comparação com experiências internacionais. Dados, Rio de Janeiro, v. 44, n. 1, 2001.

BONA, Camila de; MAY, Yduan de Oliveira. A cidadania feminina: fatores estruturantes e fraudulentos que dificultam o acesso das mulheres ao cenário político nacional. Seminário Internacional Demandas Sociais e Políticas Públicas na Sociedade Contemporânea, 16, 2019. Disponível em: <https://online.unisc.br/ acadnet/anais/index.php/sidspp/article/view/19613>. Acesso em: 08 out. 2020. BRASIL. Supremo Tribunal Federal. Medida Cautelar na Ação Direta de Inconstitucionalidade $\mathrm{n}^{\circ}$ 1.276. Relator: ministro Octávio Gallotti. Brasília, DF, 16 de agosto de 1995. Diário da Justiça. Brasília, 15 dez. 1995. Disponível em: $<$ https://jurisprudencia. stf.jus.br/pages/search/sjur35683/false>. Acesso em: 24 nov. 2020.

BRASIL. Supremo Tribunal Federal. Ação Direta de Inconstitucionalidade no 1.276. Relatora: ministra Ellen Gracie. Brasília, DF, 29 de agosto de 2002. Diário da Justiça. Brasília, 29 nov. 2002. Disponível em: <https://jurisprudencia. stf.jus.br/pages/search/sjur98085/false> Acesso em: 24 nov. 2020. 
BRASIL. Supremo Tribunal Federal. Ação Direta de Inconstitucionalidade $\mathrm{n}^{\circ}$ 1.946. Relator: ministro Sydney Sanches. Brasília, DF, 03 de abril de 2003. Diário da Justiça. Brasilia, 16 mai. 2003. Disponível em: <https://jurisprudencia. stf.jus.br/pages / search?base=acordaos \&pesquisa_inteiro_teor=false\&sinonimo $=$ true $\&$ plural $=$ true $\&$ radicais $=$ false $\&$ buscaExata $=$ true\&page $=1 \&$ pageSize $=10 \&$ queryString $=\mathrm{aDI} \% 201946 \&$ sort $=\_$score $\&$ sortBy $=\mathrm{desc}>$. Acesso em: 24 nov. 2020.

BRASIL. Supremo Tribunal Federal. Recurso em Mandado de Segurança no 26.071. Relator: ministro Carlos Britto. Brasília, DF, 13 de novembro de 2007. Diário da Justiça. Brasília, 31 jan. 2008. Disponível em: <https://jurisprudencia.stf.jus.br/pages/search/sjur90434/false>. Acesso em: 24 nov. 2020.

BRASIL. Supremo Tribunal Federal. Arguição de Descumprimento de Preceito Fundamental no 186. Relator: ministro Ricardo Lewandowski. Brasília, DF, 26 de abril de 2012. Diário da Justiça Eletrônico. Brasília, 20 out. 2014. Disponível em: <https://jurisprudencia.stf.jus. br/pages/search?base=acordaos\&pesquisa_inteiro_teor $=$ false\&sinonimo $=$ true\&plural $=$ true\&radicais $=$ false\&buscaExata $=$ true\&page $=1 \&$ pageSize $=10 \&$ queryString $=\operatorname{adpf} \% 20$ 186\&sort=_score\&sortBy $=$ desc $>$. Acesso em: 24 nov. 2020.

BRASIL. Supremo Tribunal Federal. Ação Direta e Inconstitucionalidade no 5.617. Relator: ministro Edson Fachin. Brasília, DF, 15 de março de 2018. Diário da Justiça Eletrônico. Brasília, 03 out. 2018. Disponível em: $<$ https://jurisprudencia.stf.jus.br/pages/search?base= acordaos\&pesquisa_ inteiro_teor $=$ false $\&$ sinonimo $=$ true\&plural $=$ true\&radicais $=$ false\&buscaExata $=$ true\&page $=1 \&$ pageSize $=10 \&$ queryString $=$ adi $\% 205617 \&$ sort $=\_$score $\&$ sort $B y=$ desc $>$. Acesso em: 24 nov. 2020.

BRASIL. Tribunal Superior Eleitoral. Recurso Especial Eleitoral nํㅜ군. Relator: ministro Arnaldo Versiani. Brasília, DF, 12 de agosto de 2010. Publicação: PSESS - Publicado em Sessão. Brasília, 12 ago. 2010. Disponível em: <https://inter03.tse.jus.br/sjur-pesquisa/ pesquisa/actionBRSSearchServers.do?tribunal $=$ TSE\&livre $=>$.Acesso em: 24 nov. 2020 .

BRASIL. Tribunal Superior Eleitoral. Recurso Especial Eleitoral 끈 21498. Relator: ministro Henrique Neves da Silva. Brasília, DF, 23 de maio de 2013. Diário da Justiça Eletrônico. Brasília, 24 jun. 2013. Disponível em: <https:// inter03.tse.jus.br/sjur-pesquisa/pesquisa/ actionBRSSearchServers.do?tribunal $=$ TSE\&livre= $=>$. Acesso em: 24 nov. 2020. 
BRASIL. Tribunal Superior Eleitoral. Recurso Especial Eleitoral no 149. Relator: ministro Henrique Neves da Silva. Brasília, DF, 04 de agosto de 2015. Diário da Justiça Eletrônico. Brasília, 21 out. 2015. Disponível em: <https:// inter03.tse.jus.br/sjur-pesquisa/pesquisa/ actionBRSSearchServers.do?tribunal $=$ TSE\&livre $=>$. Acesso em: 24 nov. 2020.

BRASIL. Tribunal Superior Eleitoral. Recurso Especial Eleitoral noำ 24342. Relator: ministro Henrique Neves da Silva. Brasília, DF, 16 de agosto de 2016. Diário da Justiça Eletrônico. Brasília, 11 out. 2016. Disponível em:< https://inter03.tse.jus.br/sjur-pesquisa/pesquisa / actionBRSSearch.do?toc=false\&httpSessionName=brsstateSJUT1403142839\&sectionServer=TSE\&docIndexString $=0>$. Acesso em: 24 nov. 2020.

BRASIL. Tribunal Superior Eleitoral. Recurso Especial Eleitoral nํㅜㄴ 12552. Relator: ministro Herman Benjamin. Brasília, DF, 20 de setembro de 2016. Diário da Justiça Eletrônico. Brasília, 02 ago. 2018. Disponível em: $<$ https://inter03.tse.jus.br/sjur-pesquisa/pesquisa /actionBRSSearchServers. do?tribunal $=$ TSE\&livre $=>$. Acesso em: 24 nov. 2020 .

BRASIL. Tribunal Superior Eleitoral. Consulta $\mathrm{n}^{\circ} 060025218$. Relator: ministra Rosa Weber. Brasília, DF, 22 de maio de 2018. Diário da Justiça Eletrônico. Brasília, 15 ago. 2018. Disponível em: <https://inter03.tse.jus. $\mathrm{br} /$ sjur-pesquisa/pesquisa/actionBRSSearch.do?Toc $=$ false\&httpSessionNa$\mathrm{me}=$ brsstateSJUT800938207\&sectionServer $=$ TSE\&docIndexString $=71>\mathrm{A}$ cesso em: 24 nov. 2020.

BRASIL. Tribunal Superior Eleitoral. Consulta $\mathrm{n}^{\circ} 060405458$. Relator: ministro Tarcísio Vieira de Carvalho Neto. Brasília, DF, 01 de março de 2018. Diário da Justiça Eletrônico. Brasília, 03 abr. 2018. Disponível em: <https:// inter03.tse.jus.br/sjur-pesquisa/pesquisa /actionBRSSearch.do?toc $=$ false\&httpSessionName $=$ brsstateSJUT1797373196\&sectionServer $=$ TSE \&docIndexString $=11>$. Acesso em: 24 nov. 2020.

BRASIL. Tribunal Superior Eleitoral. Prestação de Contas nº 28329. Relator: ministro Tarcísio Vieira de Carvalho Neto. Brasília, DF, 01 de fevereiro de 2019. Diário da Justiça Eletrônico. Brasília, 18 fev. 2019. Disponível em: $<$ https://inter03.tse.jus.br/sjur-pesquisa / pesquisa/actionBRSSearchServers. do?tribunal $=$ TSE\&livre $=>$. Acesso em: 24 nov. 2020 .

BRASIL. Tribunal Superior Eleitoral. Agravo de Instrumento no 33986 . Relator: ministro Luís Roberto Barroso. Brasília, DF, 15 de agosto de 2019. Diário da Justiça Eletrônico. Brasilia, 20 set. 2019. Disponível em: < https://inter03. tse.jus.br/sjur-pesquisa/pesquisa/actionBRSSearchServers.do?tribunal=TSE\&livre $=>$. Acesso em: 01 dez. 2020. 
BRASIL. Tribunal Superior Eleitoral. Recurso Especial Eleitoral no 19392. Relator: ministro Jorge Mussi. Brasília, DF, 17 de setembro de 2019. Diário da Justiça Eletrônico. Brasília, 04 out. 2019. Disponível em: <https://inter03.tse. jus.br/sjur-pesquisa/pesquisa/actionBRSS earch.do?toc $=$ false\&httpSessionName=brsstateSJUT124846254\&sectionServer $=$ TSE\&docIndexString $=1>$. Acesso em: 24 nov. 2020.

CAMBI, Eduardo. Neoconstitucionalismo e neoprocessualismo: direitos fundamentais, políticas públicas e protagonismo judiciário. São Paulo: Almedina, 2019.

GOMES, Joaquim Barbosa. A recepção do instituto da ação afirmativa pelo direito constitucional brasileiro. Revista de informação legislativa, v. 38, n. 151, p. 129-152, jul./set. 2001. Disponível em: < http:/ /www2.senado.leg.br/ bdsf/handle/id/705>. Acesso em: 11 fev. 2020.

GORTARI, Amanda dos Santos Neves. A podridão da candidatura laranja: ponderações acerca da participação feminina nas eleições brasileiras. Resenha Eleitoral - TRE/SC, Florianópolis, v. 23, n. 2, p. 187-203, 2019.

IKAWA, Daniela. Ações Afirmativas. Rio de Janeiro: Lúmen Júris, 2008. LEITE, Crislayne Moura; GUNDIM, Wagner Wilson Deiró. A participação da mulher na política brasileira e a efetividade das cotas partidárias. Resenha Eleitoral - TRE/SC, Florianópolis, v. 23, n. 1, p. 139-163, 2019.

MACEDO, Elaine Harzheim. A cota de gênero no processo eleitoral como ação afirmativa na concretização de direitos fundamentais políticos: tratamento legislativo e jurisdicional. Revista da AJURIS, Porto Alegre, v. 41, n. 133, p. 205-243, mar. 2014.

MATOS, Marlise; CYPRIANO, Breno; BRITO, Marina. Cotas de gênero para o reconhecimento das mulheres na política: um estudo comparado ações afirmativas no Brasil, Argentina e Peru. In: Congresso Brasileiro de Sociologia, 13, 2007, Recife. Anais - GT 08 - Emancipação, Cidadania e Reconhecimento. Disponível em: <http://www.sbsociologia. com.br/portal/index.php?option=com_docman\&task $=$ cat_view\&gid=137\&Itemid=171>. Acesso em: 08 out. 2020 .

NASCIMENTO, Camila Teixeira do; MOREIRA, Diogo Rais Rodrigues. Igualdade de gênero nas eleições: a fraude no processo eleitoral através de candidatas laranjas. Resenha Eleitoral - TRE/SC, Florianópolis, v. 23, n. 1, p. 165-185, 2019.

PIOVESAN, Flávia. Direitos humanos: desafios da ordem internacional contemporânea. Direitos humanos, v. 1, p. 15-37, 2006.

PIOVESAN, Flávia. Ações Afirmativas da Perspectiva dos Direitos Humanos. Cadernos de Pesquisa, v. 35, n. 124, p. 43-55, jan./abr., 2005. 
PORCARO, Nicole Gondim. Paridade de gênero na política: aprofundamento da democracia e realização dos direitos fundamentais da mulher. Revista Populus, Salvador, n. 6, p. 135-159, jun., 2019.

RAMOS, Luciana de Oliveira. Os tribunais eleitorais e as candidaturas femininas fictícias. Revista eletrônica de direito eleitoral e sistema político. Redesp, São Paulo, v. 1, n. 1, jul./dez., 2017. Disponível em: <https://apps.tre-sp.jus. br/ojs/index.php/revista EJEP/article /view/28>. Acesso em: 08 out. 2020.

RIOS, Roger Raupp. Direito antidiscriminação: discriminação direta, indireta e ações afirmativas. Porto Alegre: Livraria do Advogado, 2008.

ROCHA, Carmén Lúcia. Ação afirmativa: o conteúdo democrático do princípio da igualdade jurídica. Revista Trimestral de Direito Público, n. 15, p. 93-94, 1996.

SALES, Renata Celeste; WALMSLEY, Andrea. Mulheres no espaço político: entre as questões de gênero e o problema da concretização normativa da lei de cotas. Duc In Altum Cadernos de Direito, v. 11, n. 25, p. 171-189, set./dez., 2019.

SAPI, Cláudia Izidoro. A reserva de vagas no legislativo para mulheres: ação afirmativa para a plenitude democrática. Estudos Eleitorais, [s.1.], v. 13, n. 1, p. 15, ago. 2018. Disponível em: < https://seer.tse.jus.br/index.php/estudoseleitorais/article/view/71>. Acesso em: 11 fev. 2020.

SEVERINO, Lorena de Oliveira. Cotas para participação feminina na política brasileira: entre a necessidade e a efetividade. Resenha Eleitoral - TRE/SC, Florianópolis, v. 23, n. 1, p. 279-294, 2019.

SILVEIRA, Marilda de Paula. As consequências da identificação de candidaturas fictícias: cassação das eleitas e desincentivos à representatividade feminina na política. Resenha Eleitoral - TRE/SC, Florianópolis, v. 23, n. 2, p. 161 186, 2019.

SILVEIRA, Marilda de Paula. Democracia de gênero e seus desafios: como as ações afirmativas para participação feminina na política devem ser aprimoradas. Revista da Faculdade de Direito da UFMG, Belo Horizonte, n. 75, p. 323348, 2019.

STRECK, Lenio Luiz. Jurisdição constitucional e hermenêutica: perspectivas e possibilidades de concretização dos direitos fundamentais-sociais no Brasil. Novos estudos jurídicos, Itajaí, v. 8, n. 2, p. 250-302, 2008

Luísa Hickel Gamba - Mestranda do Curso de Mestrado Profissional em Direito da Universidade Federal de Santa Catarina (UFSC). Juíza federal da Justiça Federal da $4^{\text {a }}$ Região e ex-integrante do Tribunal Regional Eleitoral de Santa Catarina (TRE/SC), na categoria juiz federal. 